inequalities, with universities at the bottom suffering from underfunding and producing questionable quality. Many of these universities are being converted into polytechnic institutes ("applied universities"), which may contribute to the creation of a more rational system of higher education in China. While China's top soo universities have made significant progress, the pressures of massification continue to affect the institutions at the bottom of the system.

When predicting the future of Chinese higher education, it is important to recognize the reality of the system as a whole and not be mesmerized by the rapid and impressive achievements of China's top universities. Lurking within the system are deep problems that have yet to be addressed-let alone solved — and that are fundamental to the health of the higher education system in the long run.

\section{Managing Markets and Massification of Higher Education in India}

\section{N.V. VARGHESE}

N.V. Varghese is director, Centre for Policy Research in Higher Education, National University of Educational Planning and Administration, New Delhi 110016, India.E-mail:nv.varghese@nuepa.org.

$\mathrm{T}$ he higher education system in India is at a stage of revival. The sector experienced an unprecedented expansion in this century. The double-digit annual growth rate in the previous decade helped the higher education sector enter a stage of massification. With more than 700 universities, nearly 37,000 colleges, I.4 million teachers, and 3I million students, Indian higher education is a massive system, the second largest in the world after China.

\section{MARKET-FRIENDLY ReForms}

The massification of the sector reflects a change in public policy, from a state controlled, publicly funded system that experienced slow growth and provided limited access, to a system led by market principles of operation. Liberalization policies in the economic sector in the I990s encouraged a permeation of market forces and market-friendly reforms into the higher education sector, which led to a proliferation of private institutions and the explosion of student enrollments in India.
It may seem strange that while mature market economies relied on public institutions to absorb the massive demand for higher education, less developed market economies such as India relied on the market. At present, more than three-fifths of the enrollment is accounted for by private higher education institutions.

\section{Market-led massification promoted a faster growth of market-friendly study programs in technical, professional, and management domains, leading to disciplinary distortions.}

Initially, private sector involvement in higher education was in the form of sharing costs with the government. The next phase saw the emergence of self-financing and capitation (special feels that student pay at some colleges prior to entry) fee colleges, followed by private institutions attaining the status of deemed-to-be universities (a special status that state authorities can give to universities not otherwise officially recognized), and finally the status of private universities in this century.

\section{Massification and its Characteristics}

Market-led massification promoted a faster growth of market-friendly study programs in technical, professional, and management domains, leading to disciplinary distortions. This resulted also in an increase in the unemployment of graduates from these streams, leading to a decline in the demand for these study programs and the closure of some private institutions.

Massification promoted the expansion of non-university institutions and study programs awarding diploma level certifications. The non-university segment has been the fastest growing segment in higher education-the enrollment increased by 23 times, and its share in total enrollment by eight times, between 2005 and 2012 .

Higher education in India is mainly undergraduate education, which accounts for nearly 80 percent of the enrollment. The share of enrollment in graduate study programs is low and that in research programs is declining. This trend may have implications on the availability of teachers, constraining the sector even further.

\section{MASSIFICATION AND INEQUALITIES}

The massification of higher education in India is accompanied by persisting, if not widening, inequalities. While 
all regions and social groups, and both sexes, improved their status, the rate of growth varied, leading to widening inequalities. For example, between 2002-2003 and 2OII-2OI2, the gross enrollment ratio (GER) increased by three times in some states, two times in others, but was much slower yet in others. The gains in GER are the highest among states where private institutions are dominant which contributes to the widening of inequalities.

The disparities in enrollment among different social groups continue to be significant. However, the benefits of massification are more equally shared between the sexes. Although inequalities still persist, the disparities in the share of enrollment of men and women are narrowing down. In fact, in some of the states where the GER is relatively high, the gender parity index is greater than $\mathrm{I}$.

\section{Massification and Quality}

Massification has contributed to a deterioration in quality. The reckless growth of self-financing private colleges has resulted in a proliferation of institutions with poor infrastructure, less qualified teachers, and no research facilities. After performing site visits, one of the recent evaluation Committees recommended closure of 4I deemed universities because of poor quality.

\section{The disparities in enrollment among dif- ferent social groups continue to be sig- nificant.}

India has established mechanisms for external and internal quality assurance mechanisms. Since accreditation is voluntary, a major share of the institutions is not yet accredited. In a majority of institutions, the internal quality assurance units are not operational. This trend may change since the University Grant Commission has now made accreditation a necessary condition to obtain grant funding.

A new trend is that quality is affecting quantity in higher education in India. The enrollment in many private colleges - in particular technical and professional colleges - is declining due to the questionable quality of the education provided and the considerable unemployment rate of their graduates.

\section{Challenges of Governance and Management}

The existence of multiple regulatory bodies and funding arrangements makes it difficult to govern and manage the system and the institutions that are part of it. The system of affiliated colleges makes the situation worse. Universities are responsible for developing curriculum, overseeing academic standards, conducting examinations, and awarding degrees to all those enrolled in university departments and affiliated colleges. The number of colleges affiliated to some of the universities is too large to allow any meaningful academic guidance. India needs to plan for a larger number of small-size universities and autonomous colleges, and restrict the number of colleges to be affiliated.

Institutional autonomy is essential for effective management. Except for selected institutions such as the Indian Institutes of Technology (IITs) and the Indian Institutes of Management (IIMs), universities in India enjoy autonomy in theory only. State universities continue to be over-regulated and controlled by the government. Many institutions are starving for funds and are at the mercy of the government. At times, institutions complain that they receive more directives than funds from public authorities.

Undoubtedly, the level of autonomy depends on the institutional head. It is felt that the erosion of institutional authority and autonomy is a result of political influence in the selection of institutional heads. Most institutions have their own governing bodies. However, the process of nomination of the members of the governing boards is not always free from interference.

At times, granting autonomy is seen as an excuse for not extending financial support. While autonomy gives better scope for institutions to engage in resource mobilization, core funding from the government would make them less vulnerable and more effective.

\section{CONCLUSION}

The compulsion to expand higher education in India will continue. The low gross enrollment ratio, an expanding secondary school system, and an increasing number of youth provide fertile ground for further expansion. In the $2020 \mathrm{~s}$, India will have one of the youngest populations, and the largest tertiary-age population in the world. A majority of young people will live in urban areas and come from middle class families with good capacity to pay. This implies that the era of decision-making constrained by scarcity of public resources may come to an end. We may expect more market-friendly reforms in higher education in India.

The future challenge lies in expanding the system while containing inequalities and improving quality. The Indian experience shows that while market forces may be helpful to expand higher education, especially among those who have the ability to pay, the market may not be the most reliable ally to reduce inqualities and promote quality. Therefore, strategies for the future need to focus on regulating the system effectively for quality, and targeting backward 
regions and deprived groups for ensuring equity in access to higher education.

(This article is based on: Varghese, N.V. 2015. Challenges of massification of higher education in India, CPRHE Research Papers I, New Delhi.)

\section{Academic Freedom in the World's Largest Democracy}

\section{William G. Tierney and Nidhi S. Sabharwal}

William G. Tierney is university professor, Wilbur-Kieffer professor of higher education, and co-director of the Pullias Center for Higher Education at the University of Southern California. He currently has a Fulbright Fellowship to India. E-mail: wgtiern@usc.edu. Nidhi S. Sabharwal is associate professor in the Center for Policy Research in Higher Education at the National University of Educational Planning and Administration in New Delhi, India. E-mail: nidhis@nuepa.org.

$\mathrm{O}$ February 9, 20I6, a cultural program was held on the campus of Jawaharlal Nehru University (JNU) in the heart of New Delhi, India. JNU, largely a graduate institution with 8,000 students, is thought of as one of India's best universities. The faculty and students have the reputation of being from the left and vocal in opposition to the current government of Narendra Modi. There is also a vocal minority of students who are members of Akhil Bharatiya Vidyarthi Parishad (ABVP), a conservative organization closely allied with the Rashtriya Swayamsewak Sangh (RSS), another ultra-conservative Hindu nationalist group.

The event was organized by the Democratic Student Union and initially approved by the administration. The ABVP protested, however, and the administration cancelled the event. The students nevertheless went ahead with what they defined as a cultural program. The program's purpose was to commemorate through poetry, music, and art- the death of Afzal Guru, the terrorist convicted of bombing Parliament in 200I. The organizers also talked about the ongoing struggles in Kashmir, the rights of the people in the region, and the importance of self-determination. Kanhaiya Kumar, the president of the Student Union, attended the event in support.

Three days after the event, the vice chancellor let the police enter the campus and arrest Kanhaiya Kumar for sedition. Many in the country believed that speakers crossed a line by talking about Kashmir in a manner that suggested independence.

\section{Attacking the Country or Attacking Academic FREEDOM?}

The actions on and off campus have been front page news for two months. Those on the right have condemned the protest. The Home Minister of India stated, "If anyone raises anti-India slogans, tries to raise questions on the country's unity and integrity, they will not be spared." Some have argued for violence against anyone who would speak against the country; others have said the university should be shut down-that such events should never be allowed at a public university. The High Court judge who granted bail to Kanhaiya said that "the entire JNU campus suffers from some unpatriotic and anti-national infestation that requires cleansing through pro-active policing."

Others have suggested that Kanhaiya's arrest and the ensuing outcry is yet another attack on academic freedom. Since the Modi government came to power in 20I4, over 50 intellectuals have returned their medals and awards in part to protest a crackdown on academic freedom at India's universities. Others allege that a stifling of academic freedom has been behind the government's multiple forced resignations from academic and intellectual committees and organizations. Recent appointments of the Chair of the National Book Trust, the Central Advisory Board of Education, and the Indian Council of Historical Research, are examples of individuals and bodies who fall in line with the current government's policies; those who were purged from those positions were respected academics who did not necessarily agree with one or another policy of the government. Many argue that such actions have not been uncommon in the past as well.

\section{Framing Academic Freedom}

Such issues underscore the tensions of academic freedom. Except for ideologues, academic freedom is an elusive concept whose meanings and interpretations require thoughtful consideration. India is a democracy, but its definitions, for example, of what counts as sedition differs from another democracy such as the United States. The sorts of movies and books that get censored in India reflect an environment that is more conservative than in the United States. A new movie, Aligarh, depicts a relationship between a male professor and a (male) rickshaw driver. Largely based on the true story of an academic who committed suicide, the movie cannot find a broad outlet in India; numerous groups have tried to ban the movie from being seen on the campus where the professor worked. Is academic freedom a cultural term that requires a common understanding, or does the locale of the university circumscribe its meaning? The curricula in India's postsecondary classrooms are largely prescribed. Is the Indian historian and public intellectual, Romila Tharpar, correct that standardized syllabi that are 